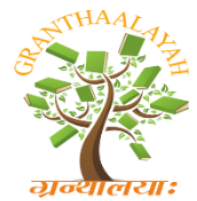

INTERNATIONAL JOURNAL OF RESEARCH GRANTHAALAYAH A knowledge Repository

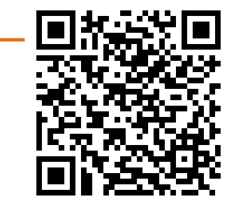

Science

\title{
BANGLADESH-INDIA RELATIONS: TRENDS AND CHALLENGES
}

\author{
Md. Shah Alam *1 \\ ${ }^{* 1}$ Assistant Professor, Department of Islamic History and Culture, University of Chittagong, \\ Bangladesh
}

\begin{abstract}
The smooth relationship between Bangladesh and India is essential for these two neighboring countries as the relationship between the two countries is historical. The relations between the two countries are also highly significant for the international relations of South Asia. The good relations between these countries originated since the liberation war of Bangladesh in 1971. Seemingly, the good relations between them have been prevailing and continuing since the independence of Bangladesh. However, the relations between Bangladesh and India has been complicated and intricate. The historical legacies have often strained the relations between these two nations instead of cementing the bond through ancestral ties. The relations have been further complicated by the prolongation in resolving the disputable issues like waters sharing treaties, immigrant infiltrations, killings in the border, and so many. Hence, most of the Bangladeshi citizens believe that relations between Bangladesh and India are imbalanced. Thus, this paper argues that a combination of all these factors has, therefore, contributed to developing anti-Indian feelings among Bangladeshi citizens. This study aims to identify and explain the presence of such an antipathy towards India among Bangladeshi people. Upon exploring the underlying causes behind the anti-Indian sentiment among Bangladeshi citizens, the paper, finally, outlines some policy implications.
\end{abstract}

Keywords: Relations; Trends and Challenges; Bangladesh-India.

Cite This Article: Md. Shah Alam. (2019). "BANGLADESH-INDIA RELATIONS: TRENDS AND CHALLENGES." International Journal of Research - Granthaalayah, 7(12), 243-251. https://doi.org/10.29121/granthaalayah.v7.i12.2019.318.

\section{Introduction}

India is one of the rising powers of Asia and trying to establish itself as a global power as well (Hall, 2010). With such a high power surrounding on three sides of the border, it is no surprise that India holds indisputable importance in the foreign policy of Bangladesh. On the other hand, as one of the closest neighbor with strategic importance in the field of geopolitics, Bangladesh has become a significant priority for the Indian foreign policymakers as well (Mukherjee et al., 2011). Nevertheless, the relationship between the countries has been somewhat erratic over the past decades (Pandey, 2011). The relationship between India and Bangladesh is very multidimensional, 
as well as involved in nature. The strengths of attachments of these two states lie in their close cultural, linguistic, and historical ties. Again, the relation of these two nations has also been strained due to several contentious issues tracing back its origin to a long time back in history (Kumar, 2010).

Therefore, considering the intricacy and multi-dimensionality of the nature of the relationship combined with the legacy of history, the relation between India and Bangladesh is an interesting topic of scholarly study. There have been previous studies on the importance of improving bilateral relations between India and Bangladesh, or about the impediments obstructing in taking the existent relationship to another level. However, there has not been a considerable amount of academic study about how the general people of these two states perceive their importance, as ally or enemy. Some Bangladeshis may consider India as a threat. Thus, there should be academic analysis to prove the existence of such discontent among Bangladeshis against India and possible reasons and arguments behind it. This research will try to look into the existence of such alleged fear and dissatisfaction among the Bangladeshis about India as well as will try to explore the possible factors or reasons behind the perceived resentment and discontent.

However, in spite of state-level initiatives to promote better relations, there is general perception existing about the peoples of Bangladesh antagonism towards India. Considering India's attempt to influence the relatively smaller nations in South Asia, it is not surprising that India has created a formidable, sometimes intimidating, image in the region (Pattanaik, 2010). Considering this fact, combining with the historical and contemporary disputable issues, the peoples of Bangladesh's perspective about their closest neighbor will be attractive as well as a significant matter of study. Together India and Bangladesh, along with Pakistan, once comprised the Greater Indian nation, were once ruled by the Mughals and British Colonizers. In the twentieth century, the Indian subcontinent became divided into three sovereign nations. However, these three nation-states have developed an intense enmity with each other instead of a shared history of hundreds of years. While Pakistan is a bête noire to both India and Bangladesh, two countries have developed a more complicated relationship over the years. India became Bangladesh's closest ally and trusted friend immediately after the War of Independence of Bangladesh in 1971 (Sikri, 2009). India sheltered Bangladeshi refugees, helped in training Bangladeshi freedom fighters, and, most importantly, vehemently opposed the Pakistani Army's atrocities in the then East Pakistan (Sisson and Rose, 1990). Therefore, it was inevitable that these two closest neighbors will turn out to be trusted allies as well. Sheikh Mujibur Rahman, the first president Bangladesh and father of the nation, said that "Friendship with India is a cornerstone of the foreign policy of Bangladesh" (Bhardwaj 2003, P. 265). However, since the late 1970s, the relationship of these two neighboring nations experienced bitterness and distrust. With the death of Sheikh Mujibur Rahman, the anti-Indian ideas began to surface and gradually established to such an extent that it was even believed that, "There is only one imminent source of danger for Bangladesh- India" (Bateman 1979, P. 783). In Bangladesh, the majority perception of India was an "expansionist" big neighbor, and public opinion became increasingly hostile against India (Talukder 1977).

While in general, the anti-Indian feelings prevailed at different extent, different political parties stigmatized and nurtured these feelings as necessary for advantages over domestic politics. The entire Bangladesh-India relationship has been characterized by "mistrust and suspicion primarily characterized Bangladesh-India relations from the mid-1970s to the end of 2008" except the period 
from 1996-2001 with Awami League in the state power (Chakma 2012). The India factor is an influential factor in domestic politics, and it is so significant that the credibility of politicians in Bangladesh is measured through their pro-India and anti-India stances (Pattanaik 2005). Apart from the historical legacies, his India phobia in Bangladesh has been intensified by some significant discord issues such as Farakka Barrage, Teesta Water Treaty, border infiltrations, transit, illegal immigrants, and killing of civilians in the border areas. There is a widespread belief among general people that the "unfair" and arrogant attitude that often India shows, even after enjoying benefits, India enjoys from Bangladesh (like transit facilities), would be impossible Bangladesh was still a part of Pakistan. Therefore, India should not undermine Bangladesh and instead offer equal respect as a sovereign state (Pattanaik 2005).

Despite many areas of disputes, the Bangladesh-India relations began to brighten up gradually in recent days (Sikri, 2009). The relationship between these two countries has considerably intensified over the last ten years. Since the accession of the Awami League government in state power in 2008, Bangladesh has taken positive attempts to maintain a good relationship with the largest neighboring nation, and arguably the most significant influence in South Asia (Ali, 2018). Owing to the favorable attitudes from the highest-level government, the interactions between Bangladesh and India have taken a positive direction, and the Indian government has taken similar actions to improve the relations. For example, during the state visit of Bangladeshi Prime Minister Sheikh Hasina in India, both pledged to combat terrorism with cooperation (Vaughn 2010). Since then, both India and Bangladesh have helped each other in fighting insurgent groups. Another critical aspect of the revitalize Bangladesh India relationship is a mutual agreement in cooperation about power and the internet, where India is helping Bangladesh meet the increasing demands for electricity, and Bangladesh supplying unused internet Bandwidth for India (Kashem 2016). The significant achievement of Bangladesh-India friendship is the Border agreement treaty in which the two countries exchanged border enclaves, which has been a major issue of contention between these two countries (Quadir 2015).

Moreover, with the newly found zeal of friendship, Bangladesh has received increasing investment and financial help from India. Amid all these upturns in Bangladesh India relations, it is still claimed that Bangladeshi people nurture distrust towards India. Although at the state level, the governments of India and Bangladesh are in closer confidence than ever, the same cannot be confidently said for the mass people of the countries. Therefore, an ambiguity about general people's perception of India continues to prevail.

It is often claimed that Bangladeshi people maintain ill feelings toward neighboring country India. Even in one case, the former Prime Minister of India, Dr. Manmohan Singh, commented that 25\% of Bangladeshi people as anti-Indian (Dikshit 2011). Despite the historical foundations of strong mutual friendship, the reasons for such alleged enmity needs to be carefully analyzed. This research focuses on the validity of such a claim surrounding Bangladeshi people's' antipathy towards India. If such assertions are found to be accurate and existing, then this study tries to find the extent of the hostility, and additionally, what reasons might have contributed to creating the antagonism towards India: historical or contemporary contentions. 


\section{Methods}

Data for this study were collected from different primary and secondary sources. Secondary sources include books, newspapers, journals, and magazines. For primary sources, a group of respondents, chosen before the interview, was invited to participate in the study. Although the initial target was to interview 50 participants, however, due to time constraints, only five participants were interviewed. The selection of research participants was made with the "Thematic sampling" process. The participants were chosen based on the criteria of age, gender, locality, nationality, and nature of residence in Bangladesh. All the participants were Bangladeshi females within a range of 18 to 30 years age and with a permanent residence in the country. The research was conducted on the participants from Chittagong, Bangladesh. At the beginning of the interviews, the participants were informed about the objectives and a brief summary of the research. They were asked to answer a set of questions prepared for this study. Since the interviews were semi-structured, hence, there have been both open and close-ended questions. Also, there were follow-up questions and subsequent discussions on the answers they provided in response to the primary set of questions. The independent and additional comments or remarks on the topic were also taken into account while discussing the results for the research using an inductive method of analysis.

The possibility of any risks for the participants has been minimized through careful concealment and protection of participants' personal identity. The participants were also provided with full freedom to deny participating in the research. Moreover, participants had the independence to escape or deny answering any question. It is highly unlikely that the study will lead to any adverse outcome; nevertheless, as a precaution, no personal information like name, age, address, and others has been mentioned in the research. All the participants are anonymously mentioned in this study. Only the principal investigator will has access to the personal information of the respondents to ensure discretion and confidentiality. Even after that if any unexpected outcome is produced, the study or the researcher will not be responsible for that, since the participants have participated voluntarily with informed consent, and they only answered on topics strictly related to the topic. Aside from this, if any participant formulates any imaginary situations/ideas harmful for him/herself, then, the research project or personnel will not take responsibility for that

This research contains a considerable amount of significance since it aims to determine the women's opinion about the bilateral relations between India and Bangladesh. India being one of the rising economic and military powers in Asia, and Bangladesh having strategic importance in the geopolitics of the Asian region, the relation between these two countries has become a key factor in each other's foreign policy agenda increasingly. As a result, numerous discussions have been done both within and outside academia about the strategic issues affecting the relationship of these two states, including an analysis of different pros and cons of their foreign policies. Domestic pressure and forces, in other words, Innenpolitik factors, are powerful agents for shaping the foreign policy of a country. Therefore, foreign policy-related agendas of many countries are more influenced by political advantages than rational decision-making. Both India and Bangladesh practice a parliamentary form of democracy. Hence, it is logical to believe that the general opinion of people, which is reflected through their participation in elections and voting for political parties with the preferred agendas, is also reflected in the policy. In the case of Bangladesh, like many other countries, foreign policy is primarily a projection of the country's socio-economic and 
political compulsions. Therefore, it is indisputable that the public opinion, particularly in the case of Bangladesh, has the potency for structuring and restructuring Bangladesh's foreign policy. Considering this power of public opinion, this paper attempts to find out the opinion of mass people on a primary level. Besides, this paper focuses on a particular age group and gender as participants. The age group of 18 to 30 years old signifies the young generation of Bangladesh. This research also focuses on the urban women of the age, as mentioned above group. Women belonging to this age group in urban areas usually have greater access to education, media, and technology. Therefore, they were able to provide conclusive and informer opinions on the research question. Therefore, in overall, this research brings forward a clearer idea about the Bangladeshi people's actual opinion on India-Bangladesh relation, which may help both the country's researchers as well as administrations to initiate further discussions, analyses and policy formulations.

\section{Results and Discussion}

The participants of this research answered questions related to the bilateral relations between Bangladesh and India. Out of the five participants, the majority considered the relationship between these two states as unequal and also believed that India occasionally interferes in the domestic events of Bangladesh. However, the majority of the participants did not consider any possibilities of any territorial expansion. Again, when they were asked about whether the recent agreements between Bangladesh and India signify an improved relationship as well as reflect Bangladeshi people's demands and expectations, the majority of them had no opinion. As an explanation for these answers, few of them commented that there is not much information about the agreements done on the government level. The news in print and electronic media about the state visits of high officials and subsequent agreements do not usually offer a neutral and in-depth analysis of the pros and cons of these agreements. They believed all the information about such agreements appears to be biased and acts as only government propaganda. Therefore, they also felt that there is not enough information to provide a sure answer about the question of transit facilities provided for India through Bangladeshi territory. They felt the exact benefits Bangladesh will obtain out of the transit deal with India is very vague, and concerned state organizations are not providing sufficient answers to satisfy the public query.

However, the majority of the participants strongly felt that the Ganges water treaty was unfair for Bangladesh. They believed India has discriminated and continues to discriminate, Bangladesh in sharing the water not only from Ganges but also from Teesta and other rivers. Again, when asked about the alleged claim about India assisting the Chittagong Hill Tracts (CHT) insurgents, the majority of them expressed no opinions. However, interestingly four out of five participants believed that the Hindu Muslim struggle does not have a role in defining the Bangladesh India relationship. Although they acknowledged the Hindu-Muslim tension had been a big issue in the past, however, at present, these differences only occasionally play a role when there is communal violence in either country. They believed the claimed fear of Hindu dominance could be true in past times. Still, as the Muslims of Bangladesh have also advanced in education, business, and other sectors of life; hence, there is no such fear that a Hindu dominance can quickly shift the power balance.

In addition, all of the participants strongly condemned the killing of civilians in the IndiaBangladesh border by the Indian security forces. They believed it is highly unlikely that there 
could be no plausible solution for stopping these killings. Moreover, in response to the question about their opinion on the foreign policy of Bangladesh for India, most of them thought that it is highly influenced by the interests of the top officials of the government. They thought the ruling party has in general a friendly view for India due to historical reasons of 1971. As a result, the present Bangladeshi foreign policy is friendlier towards India than the previous governments by other parties like the Bangladesh Nationalist Party (BNP). However, they felt there is opacity about how much Bangladesh is benefited out of these friendly policies. In spite of having extensive media coverage about any deals and issues concerning the Bangladesh-India relationship, they felt that there is an underlying bias in publishing over-enthusiastic news about the improvements in the relation of these two nations. As Bangladeshi media, as per their opinion, is often bias based on political ideologies; hence, general people are deprived of any neutral and critical analysis of the foreign policies towards India.

Moreover, their overall rating about India as a neighbor confirmed the alleged name of India as a Big Bully of South Asia. The majority of them believed India, being the largest and most powerful country of the region, often attempts to manipulate the smaller countries. They also considered many of Indian actions as uncompromising and inconsiderate in respecting the legitimate demands of Bangladesh as a neighbor. Again, as a response to the last question, two of them refused to label Bangladeshis as anti-Indians; nevertheless, they believed if India continues to be unaccommodating to Bangladesh's rightful demands in future as well, then it could lead to the rise of a serious anti-Indian feeling in the public mind. On the other hand, two other participants believed that considering the Indian government's discriminatory attitude in many issues like water sharing treaties, border-killing disputes, and others have helped in creating a very intimidating image of India. As a result, they thought Bangladeshi people could never feel or believe to be equally treated by the Indians. They believed even if there is a presence of anti-Indian feelings among many people, the responsibility of its creation lies in the Indian actions so far in dealing with Bangladesh as a sovereign neighbor. Hence, considering the overall responses from the participants of the research, it seems that the general Bangladeshis have a mixed view about India, which has a more inclination to take a negative direction than the opposite.

\section{Major Issues between Bangladesh and India}

\section{Water Sharing Treaties}

The responses of the participants in this research reflect the grievances of Bangladeshis on the issue of river water treaties in India. With an agrarian economy, a significant portion of the Bangladeshi population is associated with agricultural production, which is dependent on river water (Yanfang and Bo, 2015). Also, the river network of Bangladesh is a major transportation route. Many of these rivers are the continuations from the rivers in India; however, owing to the disputes on the share of river water (Thomas, 2017), Bangladeshi people seem to believe that India has been unfair in sharing the water (Mital, 2016). This has led to the formation of serious discontent among people. Therefore, as long as there is no convincing improvement in the watersharing treaties with India, this issue will continue to act as a negative factor in forming a public opinion of India in Bangladesh. 


\section{Border Killings}

Considering the participants' responses on the civilian killing in Bangladesh-India border, it can be deduced that there is a severe discontent among general Bangladeshis in this regard (Chatterjee, Sen, and Bengal, 2019). Although illegal border infiltrations should be contained, however, shooting the people, or perpetrators for that matter, at random, should be stopped. Hence, both governments should take more effective measures to prevent any such incidents in the future. The Bangladesh-India relation cannot establish a strong base within the general people as long as the illegal killings in the borders continue to occur (Chatterjee, Sen, and Bengal, 2019).

\section{Hindu-Muslim Tension}

Many academic scholars pointed out the Hindu-Muslim tension as a deep-rooted cause that contributes to the fear of Bangladeshi commoners about India (Husain, 2017). However, the participants seem to disagree with it. The birth of Pakistan in 1947 has been on demand for creating a land of increasing opportunities and equality for Muslims. However, equality in opportunities in new-born Pakistan can be a controversial issue, which arguably has given birth to independent Bangladesh (Jahan, 1972). Although Bangladesh has struggled as a developing country in the past four decades, naturally, there has been a development of educated class people along with other professional classes in society. Being a Muslim majority country, it is evident that there is a Muslim predominance in the educational, professional, and business fields of present Bangladesh (Kibria, 2011). This could have resulted in creating confidence among the present generation of Bangladeshis in particular, who seem to disregard the Hindu-Muslim tension as an underlying factor for the antipathy towards India.

\section{Bilateral Agreements}

In recent years, there has been an increasing number of bilateral agreements between Bangladesh India for mutual co-operation in infrastructural and economic development, and most importantly, for fighting terrorism (Bissinger, 2010). Although these initiatives have been marked as epochmaking by both states, however, the Bangladeshi people seem to be under-informed about the details and comparative benefits of these deals. There should be more opportunities for discussing the pros and cons of these bilateral agendas. Obscurity about such deals can give birth to confusion and eventually mistrust among people. In addition, since the principal beneficiaries of these deals are people; hence, they have the right to know about the outcomes of these deals. For these reasons, any decisions on providing transit facilities to India through Bangladeshi territory or other mutual agreements should be opened up for public discussion. Otherwise, the lack of transparency may create a negative perception of India among general people, which in turn can hamper the relation between these states in the future.

\section{Conclusion}

The Indo-Bangladesh working relationship is crucial for the individual purposes of both nations. Over the past years, the mutual relationship between these countries has fluctuated a lot, as a result of which a mixed perception of India has been created among the general Bangladeshis. The actions of the Indian government are generally perceived as uncompromising and respectful towards the demands of Bangladesh. Hence, both governments should take into account public emotions before formulating mutual agreements and foreign policies as well. In particular, the government of Bangladesh should adopt more transparency and accountable policies in informing 
people about ongoing bilateral economic and similar treaties. Disregarding the public perception will damage the steps for building up a meaningful, cooperative alliance between these two states. Bangladesh and India, due to the intricacy of the mutual relationship, cannot embark on an uninterrupted and stable journey for progress without co-operating. Therefore, creating a mutually friendly foreign policy is essential; however, what is more important is to take into account the people's feelings in the policy formulation. Constructive assimilation of the mass people's opinion in foreign policies can result in developing a stronger friendship between these two nations, which can be extremely advantageous for both the states as well as for the greater South Asian region.

\section{References}

[1] Alam, Aminul. "Bangladesh-India Relations: Some Recent Trends." ResearchGate. ResearchGate, Nov. 09. Web. 26 Oct. 2016.

[2] Ali, S.M., 2018. The Current and Future State of India-Bangladesh Relations. Strategic Analysis, 42(5), pp.529-537.

[3] Barbhuiya, Shelly. "INDIA-BANGLADESH RELATIONS: Issues and Challenges." Himalayan and Central Asian Studies 13.4 (2009): 35.

[4] Bateman, C.H., 1979. National Security and Nationalism in Bangladesh. Asian Survey, 19(8), pp.780-788.

[5] Bhardwaj, S., 2003. Bangladesh foreign policy vis-a-vis India. Strategic Analysis, 27(2), pp.263278.

[6] Bissinger, J., 2010. The maritime boundary dispute between Bangladesh and Myanmar: Motivations, potential solutions, and implications. asia policy, (10), pp.103-142.

[7] Chakma, Bhumitra. "Bangladesh-India Relations: Sheikh Hasina's India-Positive Policy Approach." (2012).

[8] Chatterjee, U., Sen, A. and Bengal, M.W., 2019. The emerging contour of Indo-Bangladesh relationship-A human right aspects. Transactions, 41(1), p.91.

[9] Dikshit, Sandeep. "Prime Minister's Comment on Bangladesh Raises Eyebrows." The Hindu [Chennai] 1 July 2011: n. pag. The Hindu. The Hindu, 1 July 2011. Web. 28 Oct. 2016.

[10] Hall, I., 2010. The other exception? India as a rising power. Australian Journal of International Affairs, 64(5), pp.601-611.

[11] Hossain, Ishtiaq. "Bangladesh-India Relations: Issues and Problems." Asian Survey 21.No 11 (1981): 1115-128. Jstor. Web. 26 Oct. 2016.

[12] Husain, T., 2017. Counter Terrorism Approaches: With Reference to Bangladesh. ABC Journal of Advanced Research, 6(1), pp.9-16.

[13] Jahan, R., 1972. Pakistan: Failure in national integration. Columbia University Press.

[14] Kashem, Md Abul. "Recent Issues in Bangladesh-India Relations: A Bangladeshi Perspective." Space and Culture, India 4.1 (2016): 19-24.

[15] Kibria, N., 2011. Muslims in motion: Islam and national identity in the Bangladeshi diaspora. Rutgers University Press.

[16] Kumar, A., 2010. SHAIKH HASINA'S VISIT TO INDIA AND THE FUTURE OF INDOBANGLADESH RELATIONS. Asian Affairs, 41(3), pp.422-435.

[17] Maniruzzaman, Talukder. "Bangladesh in 1976: struggle for survival as an independent state." Asian Survey 17.2 (1977): 191-200.

[18] Mital, A.R., 2016. Indo-Bangladesh water sharing issues. International Journal of Humanities and Social Science Research, 2(11), pp.7-11.

[19] Mukherjee, R. and Malone, D.M., 2011. Indian foreign policy and contemporary security challenges. International Affairs, 87(1), pp.87-104.

[20] Pandey, P., 2011. India-Bangladesh relations: need for new approach. 
[21] Pattanaik, S.S., 2010. India's neighbourhood policy: Perceptions from Bangladesh. Strategic Analysis, 35(1), pp.71-87.

[22] Pattanaik, Smruti S. "Internal Political Dynamics and Bangladesh's Foreign Policy towards India." Strategic Analysis 29.3 (2005): 395-426.

[23] Sikri, V., 2009. India-Bangladesh relations: The way ahead. India Quarterly, 65(2), pp.153-165.

[24] Sisson, R. and Rose, L.E., 1990. War and secession: Pakistan, India, and the creation of Bangladesh. Univ. of California Press.

[25] Thomas, K.A., 2017. The river-border complex: a border-integrated approach to transboundary river governance illustrated by the Ganges River and Indo-Bangladeshi border. Water International, 42(1), pp.34-53.

[26] Vaughn, Bruce. "Bangladesh: Political and Strategic Developments and US Interests." Library of Congress Washington DC Congressional Research Service, 2010.

[27] Yanfang, L. and Bo, L., 2015. Sub-Regional Cooperation and the Development of Commercial and Trade Ties between Bangladesh, China, India and Myanmar. South Asian Studies, (1), p.9.

*Corresponding author.

E-mail address: shah1alamdu@ yahoo.com 